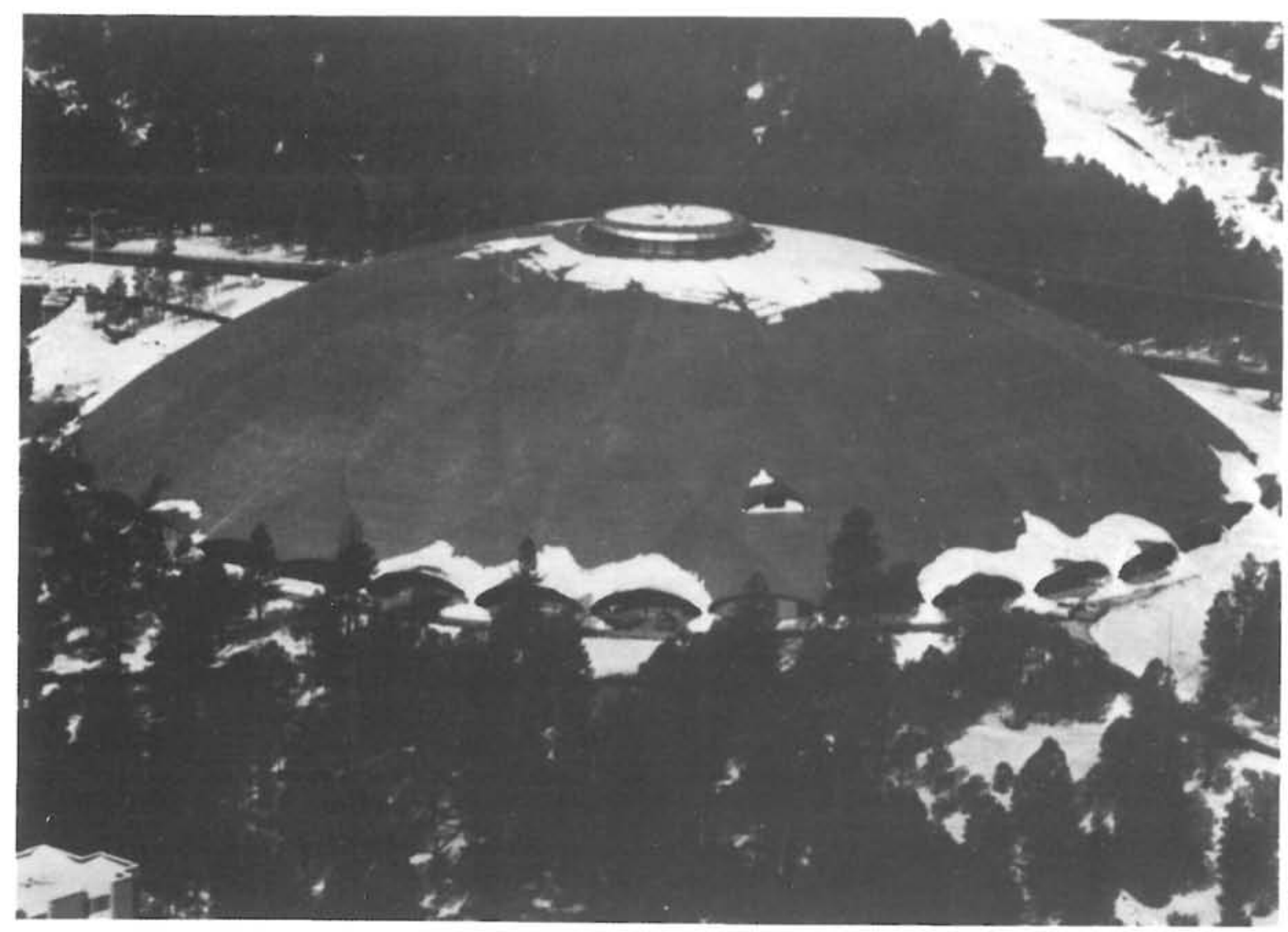

\title{
Material utilizado en la construcción de estructuras laminares
}

John K. Parsons, ingeniero

886-37

\section{sinopsis}

Este artículo trata de los materiales empleados en las distintas formas de estructuras laminares: esféricas. cilindricas e hiperbólicas.

De una manera especial se ven las características, tanto geométricas como estructurales, de la bóveda reticulada esférica "ENSPHERE» construida con madera laminada su comportamiento frente a las diversas cargas, el mótodo seguido versas cargas, el mécido para su análisis estructural, asi como los diversos ensayos realizados.
La bóveda "ENSPHERE» es una bóveda esférica reticulada de madera construida en la Universidad de Arizona del Norte en Flagstaff, Arizona, USA, la cual está situada a una altitud de $2.100 \mathrm{~m}$, en una zona montañosa poblada de pinos. La temperatura varía desde los $35{ }^{\circ} \mathrm{C}$ bajo cero hasta los $33{ }^{\circ} \mathrm{C}$ sobre cero; por esta razón la Universidad ha intentado realizar una construcción que permita a las personas despreocuparse del tiempo.

Esta bóveda de $153 \mathrm{~m}$ de diámetro, soportada por 36 pilares de 1,52 $\mathrm{m}$ de alto, se construyó sobre un terreno parcialmente rellenado. De esta manera se consiguió un mínimo de desmonte y terraplén $y$, además, una reducción de costo. El coste total, de 580.000 .000 de pesetas, es considerablemente menor que el de otros edificios similares. 


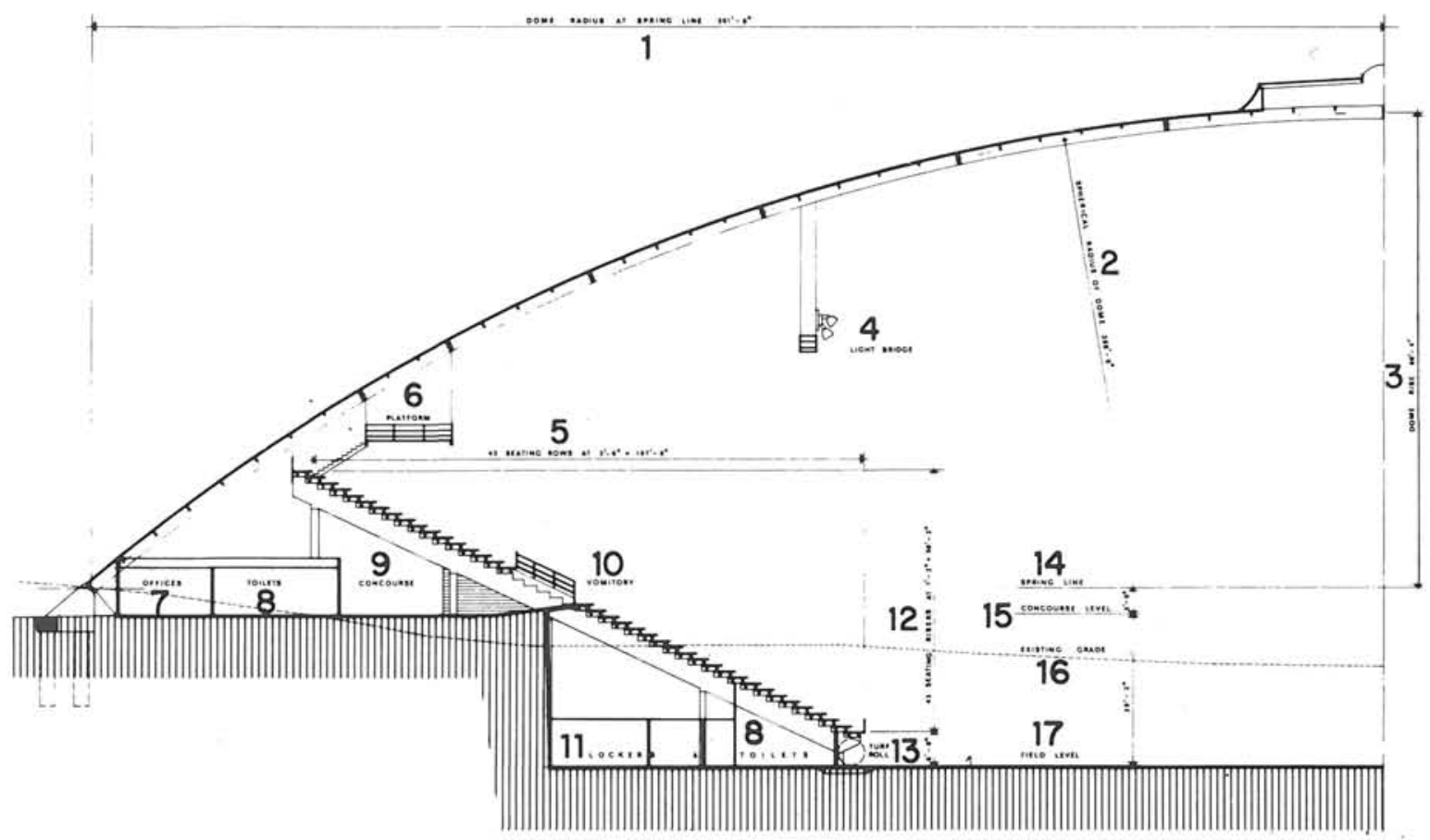

De los varios métodos de construcción, con diversos materiales, se eligió el de una bóveda esférica reticulada de madera laminada.

Las estructuras de grandes luces son consideradas actualmente, por muchos ingenieros estructurales, como gastos superfluos que sólo excepcionalmente pueden realizarse. La bóveda «ENSPHERE» significa un cierto avance en la lucha contra esta tendencia. El uso de la madera para estas estructuras no tenía precedente, pero a pesar de ello se consiguió una aparente simplicidad que es el sello de muchas grandes estructuras. La bóveda consiste en una estructura relativamente ligera de elementos triangulares, de madera laminada, unidos por conexiones de acero. Las correas, que no se consideran parte de la estructura primaria, soportan una cubierta de madera cuyos elementos están enlazados por el sistema de ranura y lengüeta. Las correas y la cubierta rigidizan la bóveda proporcionando sujeción lateral, pero se considera que no contribuyen a la acción de la estructura laminar.

La geometría de la bóveda «ENSPHERE» es la siguiente:

1) Radio esférico: $118,6 \mathrm{~m}$.

2) Flecha sobre pilares: $28,0 \mathrm{~m}$.

3) Altura de la clave sobre el terreno: $38,71 \mathrm{~m}$.

4) Angulo de la línea de arranque: $40,31^{\circ}$.

5) Area de la superficie esférica: $20.866 \mathrm{~m}^{2}$.

6) Area de la base: $18.387 \mathrm{~m}^{2}$.
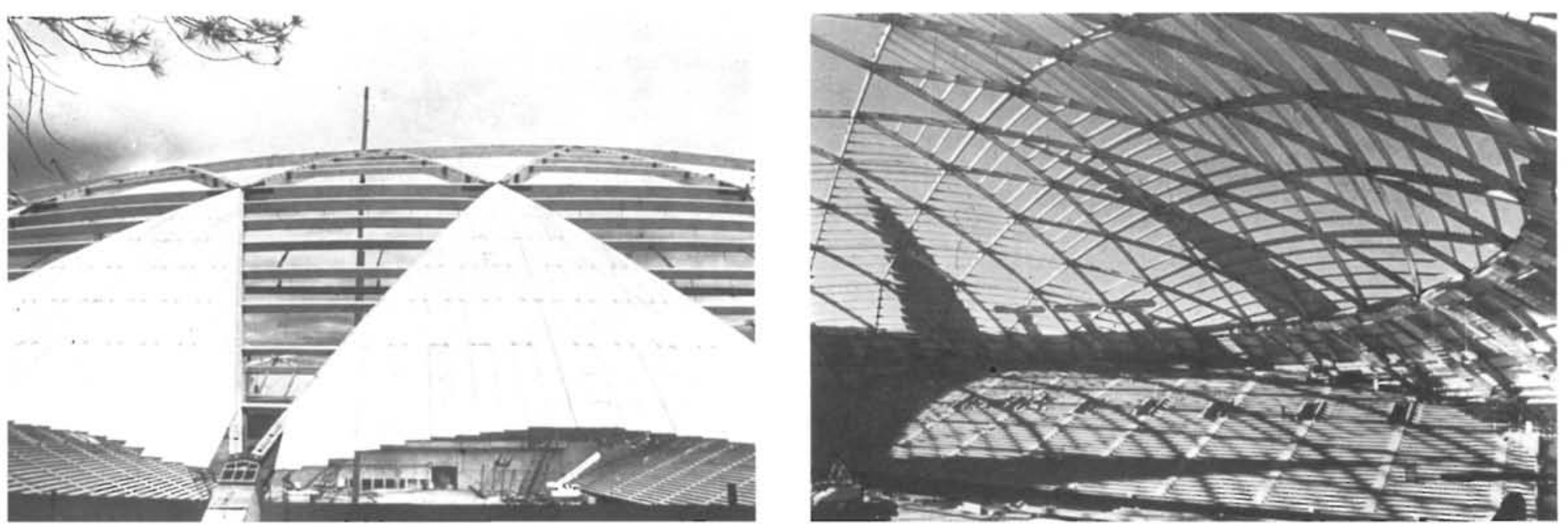

1.- Radio de la bóveda desde la cota de curvatura $(76,50 \mathrm{~m})$. 2.-Radio esférico de la bóveda $(118,25 \mathrm{~m})$. 3.-Flecha de la bóveda $(27,53 \mathrm{~m}) .4$.-Puente de luces. 5. -43 filas de asientos $(32,75 \mathrm{~m})$. 6.-Plataforma. 7.Despachos. 8.-Aseos. 9.-Ac. ceso. 10.-Vomitorio. 11.-Ves tuarios. $12 .-43$ alturas de gra das $(15,25 \mathrm{ml}$ - 13. Rodillo del ésped 14.- Cota de curvatura 15. - Cota de acceso. 16.-Grada existente. 17.-Cota de campo. 

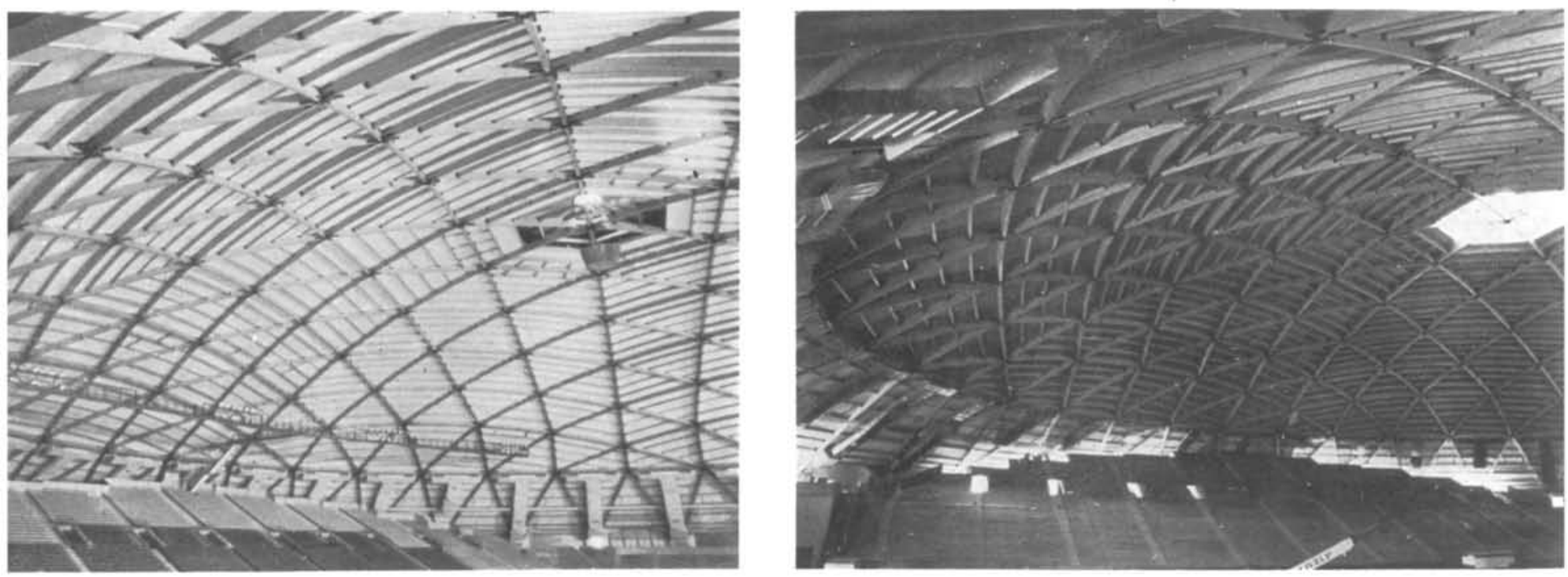

La bóveda consiste en 6 secciones idénticas, de $60^{\circ}$, que se extienden desde la clave de la bóveda hasta el último círculo máximo de 122,53 $\mathrm{m}$ de diámetro. Una viga-anillo postensada, de 1,22 $\times 0,91 \mathrm{~m}$, moldeada monolíticamente con una losa de hormigón armado, resiste los empujes como si fuese una viga continua circular postensada con cordones de $\varnothing 12,7 \mathrm{~mm}$ y $1.201 \mathrm{kn}$ de resistencia.

La mayor parte de las bóvedas de madera, proyectadas y construidas hasta la fecha, tienen conexiones de pasador en los nudos. Con objeto de hacer más económica la realización de grandes bóvedas se ha desarrollado un nuevo tipo de conectador capaz de proporcionar un alto grado de empotramiento. Los conectadores se fabricaron con placas de acero en tres tipos de unidades. La unidad exterior o S-3 se llevó a cabo con placas cuyo espesor varía desde 16 hasta $25 \mathrm{~mm}$. Se conectaron a los estribos con 6 pernos de anclaje de $\varnothing 50,80 \mathrm{~mm}$ y $1,30 \mathrm{~m}$ de largo. Las fuerzas axiles máximas son $2.379,8 \mathrm{kn}$ en compresión y 645 kn en tracción. El esfuerzo tangencial máximo es de 422,58 kn.

Los conectadores interiores o unidades S-1 se fabricaron en forma de caja hexagonal, con rigidizadores interiores. El material varía desde 9,53 $\mathrm{mm}$ en los nervios hasta $28,58 \mathrm{~mm}$ en las placas. La conexión de las vigas de madera laminada a los conectadores S-1 se llevó a cabo mediante pernos con tuercas, en ambas cabezas, soldados a las unidades S-2 existentes entre las unidades S-1 y atornilladas desde el interior con la fuerza propia. Hay una unidad S-2 atornillada en la parte superior e inferior de cada viga de madera laminada.

La estructura se analizó con la ayuda de un programa de computador para estructura espacial tridimensional, llamado GENSAP. Se comprobó después con el programa STRESS, desarrollándose posteriormente en la Pacifica Technology de San Diego, California, tres nuevos programas: primero, considerando la estructura como una viga espacial gigante; segundo, como una estructura espacial tridimensional, con miembros rectos, y tercero, con miembros curvos. La geometría, las propiedades de los materiales junto con las diversas solicitaciones de cargas se perforaron en tarjetas de computador. El programa GENSAP utiliza el método de elementos finitos de rigidez directa y la descomposición de la matriz para resolver los desplazamientos de las juntas, las fuerzas y reacciones de los elementos. 

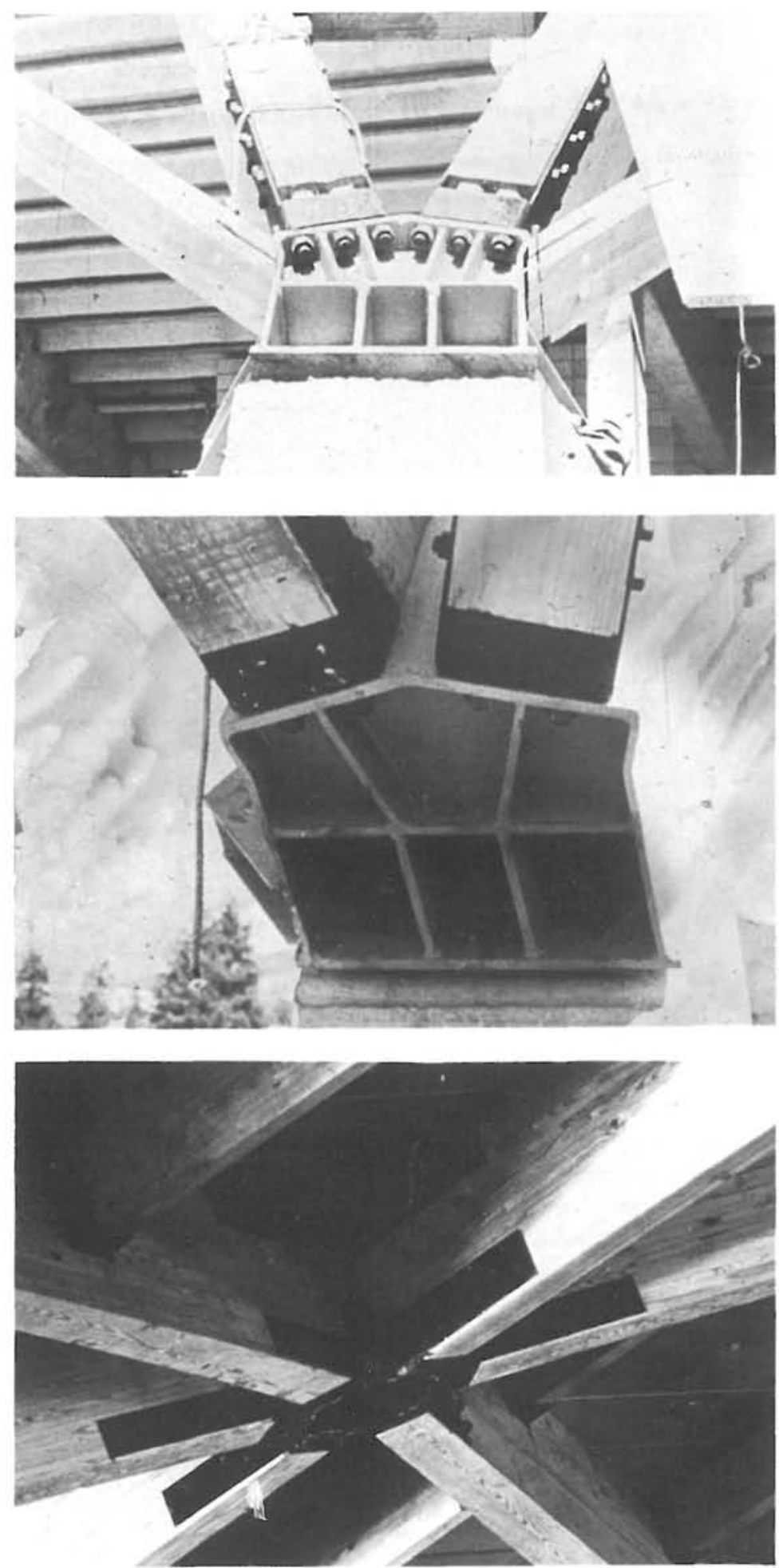

Las matrices de rigidez de los elementos se forman siguiendo la teoría de la deformación. El programa analizó la estructura como una de tipo espacial, tridimensional, con las juntas conectadas mediante pasadores y con todos los elementos rectos entre nidos. Como todos los elementos son curvos, con el mismo radio esférico, actuarán como arcos, por lo que el programa resultante tendrá respuestas que están un poco del lado conservador. Al estar todos los elementos físicamente conectados sólo por sus puntos extremos, la matriz de rigidez de los elementos es una representación verdadera de la rigidez de dichos elementos.

Se realizaron ensayos de flexión de los conectadores en la Universidad de Washington, situada en Seattle, Washington, U.S.A. Los resultados de estos ensayos indicaron que se podía alcanzar un grado de fijeza en los extremos superior, al 80 por 100 , usando pernos apretados de manera apropiada. La aptitud para desarrollar momentos negativos en los nudos da como resultado una estructura más rígida y económica. Es importante conocer el grado de empotramiento en los nudos son objeto de encontrar exactamente los puntos de inflexión y determinar la longitud no apoyada de cada elemento principal.

Para encontrar la combinación de cargas que produce la tensión crítica de proyecto se investigaron un total de 15 cargas elementales y 24 combinaciones de cargas. Se analizaron los efectos de las cargas de nieve en combinación con el peso propio y la fuerza del viento. Los elementos principales de madera laminada se ensayaron para la combinación de tensiones que resultan de la actuación del máximo momento flector obtenido, con un grado de empotramiento en los extremos de los nudos del 50 por 100 junto con el axil apropiado. En el proyecto de las conexiones nodales se supuso que actuaban fuerzas axiles con el 100 por 100 de empotramiento.

Por otra parte, los análisis matemáticos del pandeo de una estructura laminar son poco convincentes, pues los resultados obtenidos, siguiendo la opinión de diversos autores, pueden variar en un porcentaje del 300 por 100 . Una vez que los ensayos de las juntas demostraron que existía un alto grado de continuidad dentro del armazón de la bóveda, los análisis de pandeo presentan más consistencia. 
La mayor economía debida a los empotramientos de los nudos se produce en bóvedas de alrededor de 60,96 m de diámetro. De hecho, otras dos bóvedas reticuladas de madera, que están ahora en construcción en Flagstaff, Arizona, una de $48,77 \mathrm{~m}$ de diámetro y otra de $36,58 \mathrm{~m}$ de diámetro, se han proyectado con conexiones de pasador.

Un estudio de la estructura laminar se hizo de la manera siguiente:

1. - Multiplicando la deformada obtenida mediante el computador por $21 / 2$, estableciendo una nueva geometría deformada y haciendo un nuevo recorrido del computador. Todas las tensiones y desplazamientos estaban dentro de lo permitido.

2. - Multiplicando la flexión original por 5 se obtuvo que todas las tensiones y desplazamientos estaban dentro de lo permitido, excepto en la clave donde el anillo superior (seis elementos) estaba ligeramente sobretensionado y por ello se incrementaron sus dimensiones.

Tres tipos de pandeo pueden ocurrir en las estructuras laminares reticuladas: pandeo general, pandeo local, y pandeo de los elementos.

1. - El pandeo general se produce cuando un área relativamente grande de la estructura laminar se convierte en inestable, y un número relativamente grande de juntas o nudos están incluidos en la deformación.

2. - El pandeo local se produce cuando se deforma un nudo junto con sus elementos adyacentes.

3. - Pandeo local del elemento o carga crítica de Euler.

Mucho se ha escrito en los últimos años acerca de la estabilidad de las bóvedas laminares, pero no hay todavía bastante trabajo experimental sobre cuáles deben ser los criterios específicos de proyecto. Está claro, no obstante, que ciertos parámetros afectan bastante a la estabilidad. Se ha demostrado experimentalmente que muchas condiciones de borde o contorno pueden dar como resultado una carga de pandeo menor que la prevista. Las desviaciones respecto a una superficie perfecta pueden también reducir grandemente la carga de pandeo. La deformación de fluencia del material es un importante parámetro en el pandeo de la lámina, así como en su erección y fabricación. Hasta ahora las estructuras laminares no han sido tan estudiadas como por ejemplo, las vigas o los pilares, por lo que los autores de esta bóveda, aunque usaron la mayor información posible de otras estructuras laminares, sólo las sirvió de una manera teórica, pues una estructura de este tipo y tamaño no se había construido todavía. La mayor bóveda reticulada de madera anteriormente construida había sido una de 106,68 m de diámetro, en Salt Lake City, Utah, USA, con conexiones simples en los nudos. En el dimensionamiento contra el pandeo, lo primero que se intenta es determinar la intensidad de la carga con la que es posible la bifurcación del equilibrio. Los puntos en los que se cortan los caminos de equilibrio se llaman puntos de bifurcación. El punto de bifurcación es otro de los conceptos centrales en el análisis contra pandeo. En las investigaciones se considera un estado cercano al de equilibrio, infinitamente cerca del estado no deformado.

De este modo, considerando diariamente pequeñas deformaciones, se pueden menospreciar los componentes no lineales del desplazamiento (teoría lineal).

Después de superar la carga crítica lineal, el comportamiento de la estructura ya sólo puede ser descrito por la teoría no lineal, debido a que los componentes no lineales del desplazamiento normal a la superficie de la lámina deben ser tomados en consideración. Usando los resultados de la teoría no lineal podemos clasificar las láminas según su capacidad de soportar la carga de pandeo. Para poder dimensionar una estructura contra pandeo lo primero que necesitamos conocer es si su capacidad para soportar la carga aumenta o disminuye después del pandeo. Teóricamente, debemos establecer dos condiciones, cuyo cumplimiento asegura que la estructura incrementa la capacidad de soporte de la carga después del pandeo: 
1. - La estructura deberá poder redistribuir las cargas desde las partes más débiles a las más duras.

2. - La redistribución de tensiones debe ser físicamente posible en toda la estructura, incluyendo los apoyos.

Generalmente se requieren ensayos en modelo reducido, con objeto de comprobar esas condiciones.

Las bóvedas esféricas representan una de las primeras aplicaciones de las estructuras laminares. Las bóvedas de hormigón son relativamente fáciles de proyectar por la teoría de la membrana para cargas uniformes. En la clave de la bóveda, las tensiones son de compresión. La tensión en la circunferencia cambia a tracción, a una distancia angular de $51,8^{\circ}$ de la clave. Una bóveda esférica de hormigón se proyectó en Arizona, U.S.A., moldeada sobre un montón esférico de tierra. La bóveda tiene $48,77 \mathrm{~m}$ de diámetro y pesa $907.184 \mathrm{~kg}$. Las columnas están desigualmente espaciadas alrededor del perímetro, con lo que se introduce torsión en la viga-anillo. La separación entre columnas varía desde 6,10 $\mathrm{m}$ hasta 15,85 . Dos vanos de $12,19 \mathrm{~m}$ y otros dos vanos de $15,85 \mathrm{~m}$ acomodan cuatro plataformas giratorias, con lo que se consigue que el auditorio ocupe una habitación grande, o bien, un auditorio más pequeño con cuatro salas de lectura, o alguna combinación de éstas.

Una ménsula para el control de la altura de la bóveda se situó en la parte superior de ésta desde la que el operador puede controlar los 17 gatos hidráulicos como un todo o individualmente. Si en un apoyo la altura varía $6,35 \mathrm{~mm}$, respecto a los otros, las operaciones con los gatos se pararán automáticamente y el operador podrá entonces hacer funcionar individualmente cada gato hasta que todos los apoyos tengan la misma elevación.

La carga máxima de ascensión para cada gato varía desde 366,10 hasta $689,5 \mathrm{kn}$, con una diferencia máxima de ascensión entre los gatos adyacentes de 252,7 kn.

El molde de tierra se formó a base de material local, enrasado hasta la propia forma esférica y cubriéndose después con una película de $0,23 \mathrm{~mm}$ de vinilo que servía para mantener la cohesión. Después se colocó el acero para armaduras. Luego se moldeó la viga de hormigón, siendo parcialmente tensado con una compresión inicial de 1.121,1 kn, con lo que resulta una tensión de compresión de $1.496 \mathrm{mPa}$. Más tarde se aplicó resina epoxy a las juntas de construcción, y la lámina de hormigón se bombeó in situ, aplicándose posteriormente una fuerza postensada de $2.446,5 \mathrm{kn}$.

\section{Geometría:}

- Radio esférico

$54,59 \mathrm{~m}$

- Altura .. $5,49 \mathrm{~m}$

- Peso

- Espesor.

- Viga-anillo $907.184,00 \mathrm{~kg}$ $101,60 \mathrm{~mm}$ $609,60 \mathrm{~mm} \times 1.219,20 \mathrm{~mm}$

La bóveda se comprobó a torsión, flexión, tensiones debido a la temperatura, fuerzas laterales y efectos de acortamiento del postensado.

La Glass y Garden Church, en Scottsdale, Arizona, USA, es una bóveda de hormigón de 36,58 $\mathrm{m}$ de diámetro, con una viga en voladizo situada por fuera de la viga-anillo.

\section{Geometría:}

- Diámetro horizontal

$36,58 \mathrm{~m}$

- Radio esférico

$36,73 \mathrm{~m}$

- Altura

$4,88 \mathrm{~m}$

- Espesor....

$101,60 \mathrm{~m}$

- Viga-anillo en tracción

$533,40 \mathrm{~mm} \times 914,40 \mathrm{~mm}$

- Parte superior de la viga en compresión $304,80 \mathrm{~mm} \times 304,80 \mathrm{~mm}$ 
Dos bóvedas de hormigón se construyeron en el estado de Connecticut, U.S.A.: la planta de fabricación Macton y la planta de fabricación P.T.A. Ambas se proyectaron para cargas de nieve y huracanes, y también para cargas concentradas de grúas.

Sus características más importantes son las siguientes:

\section{Geometría MACTON:}

- Diámetro horizontal

$40,50 \mathrm{~m}$

- Radio esférico

$45,90 \mathrm{~m}$

- Altura

$3,40 \mathrm{~m}$

- Espesor

$101,6 \mathrm{~mm}$

- Carga máxima concentrada en la clave y en la viga-anillo

$66,70 \mathrm{kn}$

- Viga-anillo en tracción..................................

$609 \mathrm{~mm} \times 792 \mathrm{~mm}$

- Fuerza de postensado $1.765,00 \mathrm{kn}$
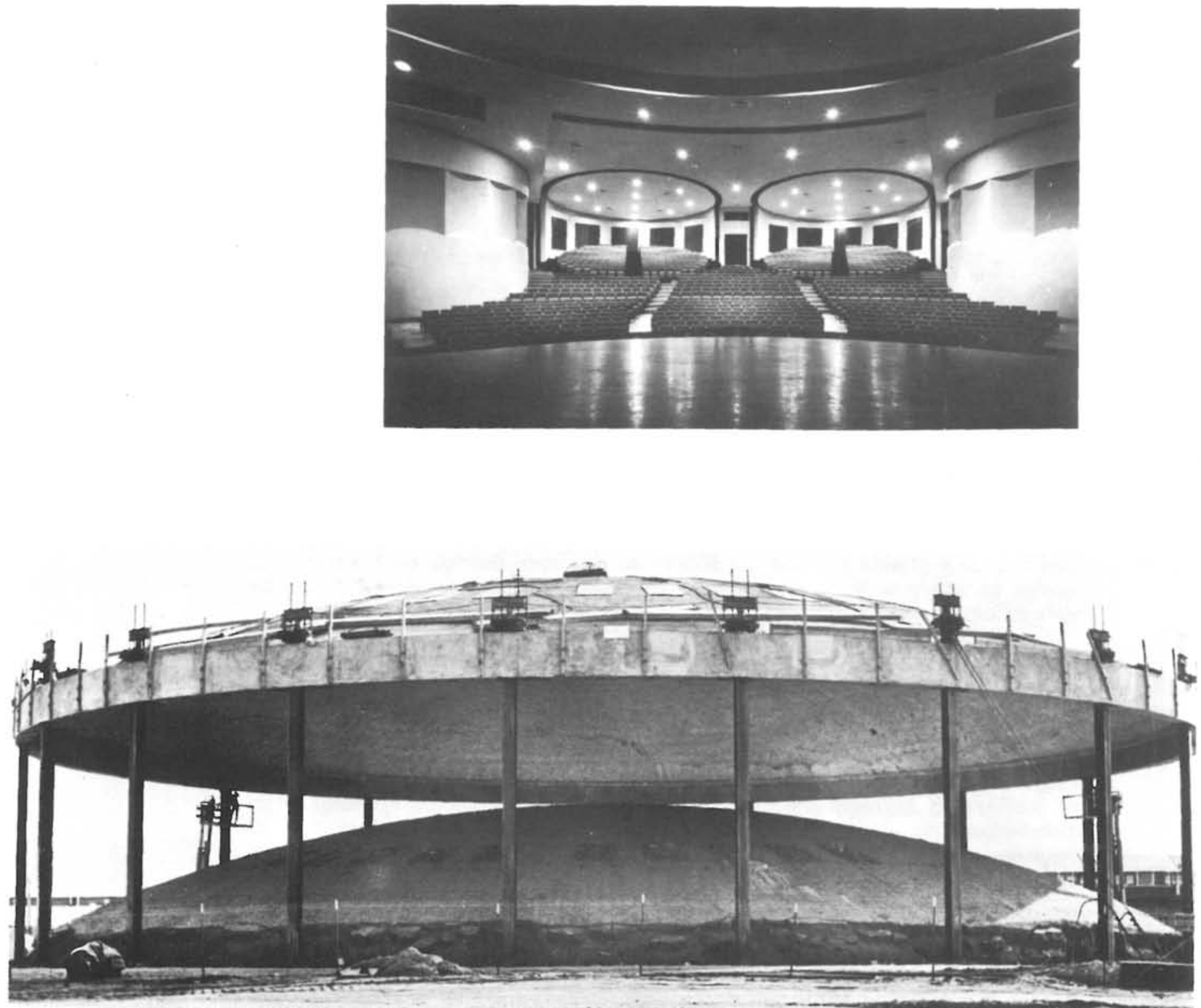

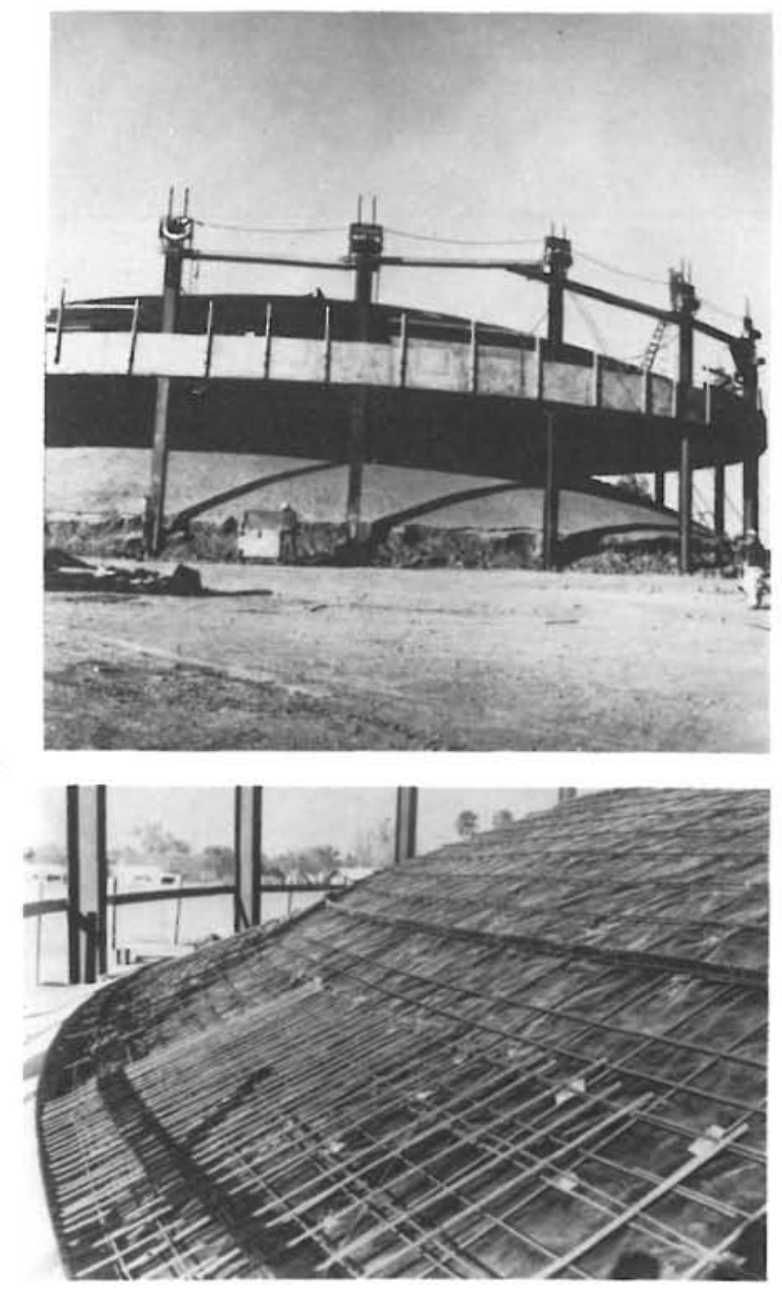

Geometría P.T.A.

- Diámetro horizontal ...................................

- Radio esférico

- Altura

- Espesor ....................................................

- Carga máxima concentrada en la clave ..........

- Carga máxima concentrada en el exterior ......

- Viga-anillo en tracción.

- Fuerza de postensado
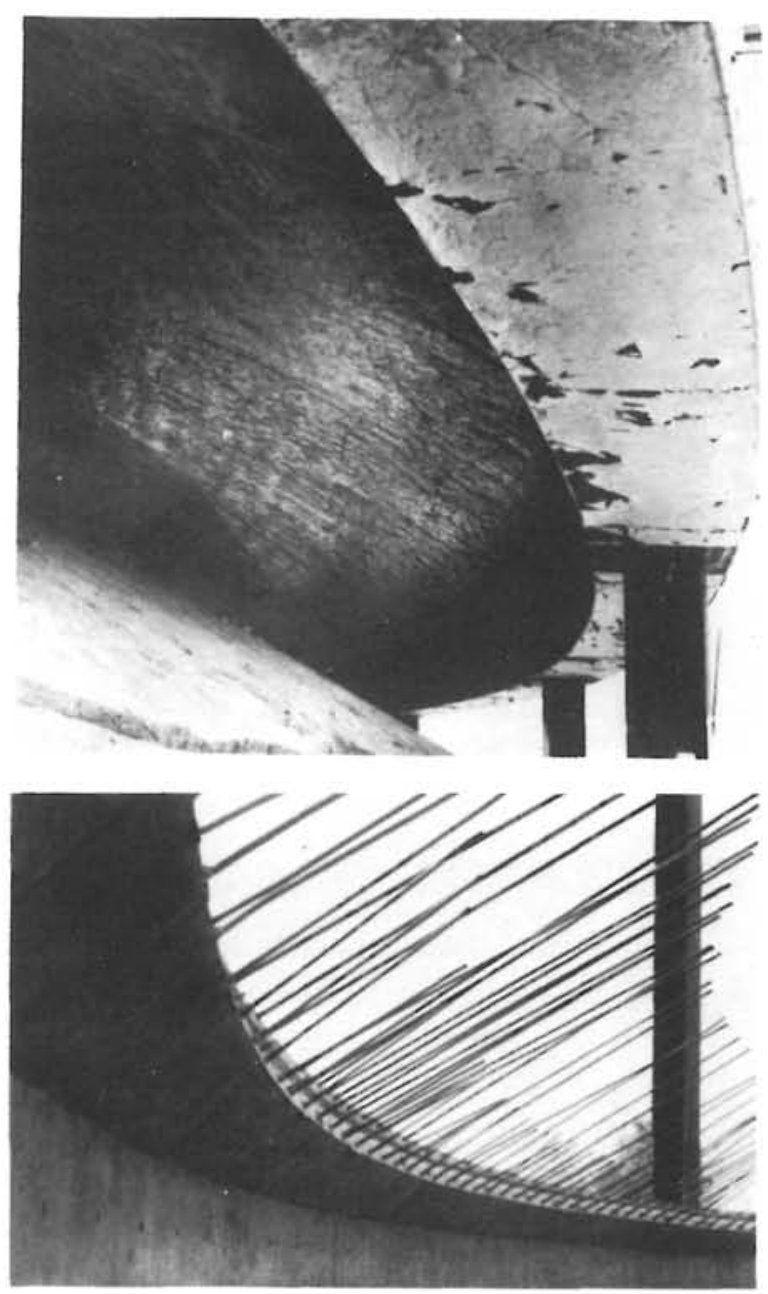

$30,50 \mathrm{~m}$

$39,60 \mathrm{~m}$

$3,00 \mathrm{~m}$

$127 \mathrm{~mm}$

$66,70 \mathrm{kn}$

$75,60 \mathrm{kn}$

$457,20 \mathrm{~mm} \times 533,40 \mathrm{~mm}$

$1.544,40 \mathrm{kn}$

Una bóveda de forma dentada, de $38,9 \mathrm{~m}$ de diámetro, dividida en 12 segmentos iguales se proyectó y construyó en Scottsdale, Arizona. La estructura laminar varía de espesor desde $76,2 \mathrm{~mm}$ hasta $0,92 \mathrm{~m}$.

Las vigas incrementan su espesor desde la viga en forma de $V$, de $0,46 \mathrm{~m}$ de canto en el apoyo hasta $177,8 \mathrm{~mm}$ en la clave.

El constructor realizó dos juegos de encofrados que se utilizaron seis veces cada uno, con lo que se consiguió un bajo costo. Un soporte central de $3,05 \mathrm{~m}$ se erigió en primer lugar, y permaneció in situ durante todo el tiempo mientras se realizaba el hormigonado. Se hormigonaron dos segmentos opuestos, desmontándose posteriormente los encofrados, volviendo a colocarlos en la posición siguiente y hormigonando otros dos segmentos opuestos. Este procedimiento se siguió hasta la terminación.

El mismo ingeniero estructural que realizó la bóveda "ENSPHERE» proyectó otras cinco bóvedas de hormigón en Tempe, Arizona, USA, en la Universidad del Estado. Dos de dichas bóvedas tienen un diámetro de $3,05 \mathrm{~m}$ y una altura de $3,66 \mathrm{~m}$ con losas de 101,6 mm de espesor. La viga-anillo se postensó con una fuerza de $993,3 \mathrm{kn}$. 
Otras dos estructuras de esta Universidad se cubrieron con una bóveda de hormigón de 101,6 mm de espesor, 27,4 m de diámetro y una altura de 3,35 m. Se apoyan en columnas monoliticas prefabricadas.

Se proyectó otra bóveda de hormigón con una elevación de 1,93 $\mathrm{m}$ en la misma Universidad. La viga-anillo tiene una fuerza de postensado de 667,2 kn.

Una estructura laminar de ferrocemento, de 22,22 $\mathrm{mm}$ de espesor y proyectada para cargas de nieve de $479 \mathrm{kPa}$ se construyó en Lake Tahoe, California, USA. La cubierta de la residencia Oehlmen se compone de 4 láminas.

La colocación de la armadura para esta obra se hizo de la manera siguiente:

1. a) Una capa de varillas de metal expandido, de $1,59 \mathrm{~kg}$, colocada a $45^{\circ}$ de la cara interior de las barras transversales.

b) Una capa de varilla de metal expandido, de $1,59 \mathrm{~kg}$, colocada a $45^{\circ}$ de las barras transversales formando un ángulo recto con la primera capa.

c) Una capa de $25,4 \mathrm{~mm}$ de mallas de alambre calibre 20 .

2. Dos capas de redondos de $\varnothing 6,35$ colocados a $45^{\circ}$ con las barras transversales y formando ángulo recto entre ellas.

3. Capa exterior consistente en tres capas de $25,7 \mathrm{~mm}$ (mallado de alambre calibre 20 ) y una capa final de $12,7 \mathrm{~mm}$ (mallado de alambre calibre 20 ).

La resistencia de proyecto a compresión fue de $34,47 \mathrm{mPa}$ en 28 días.
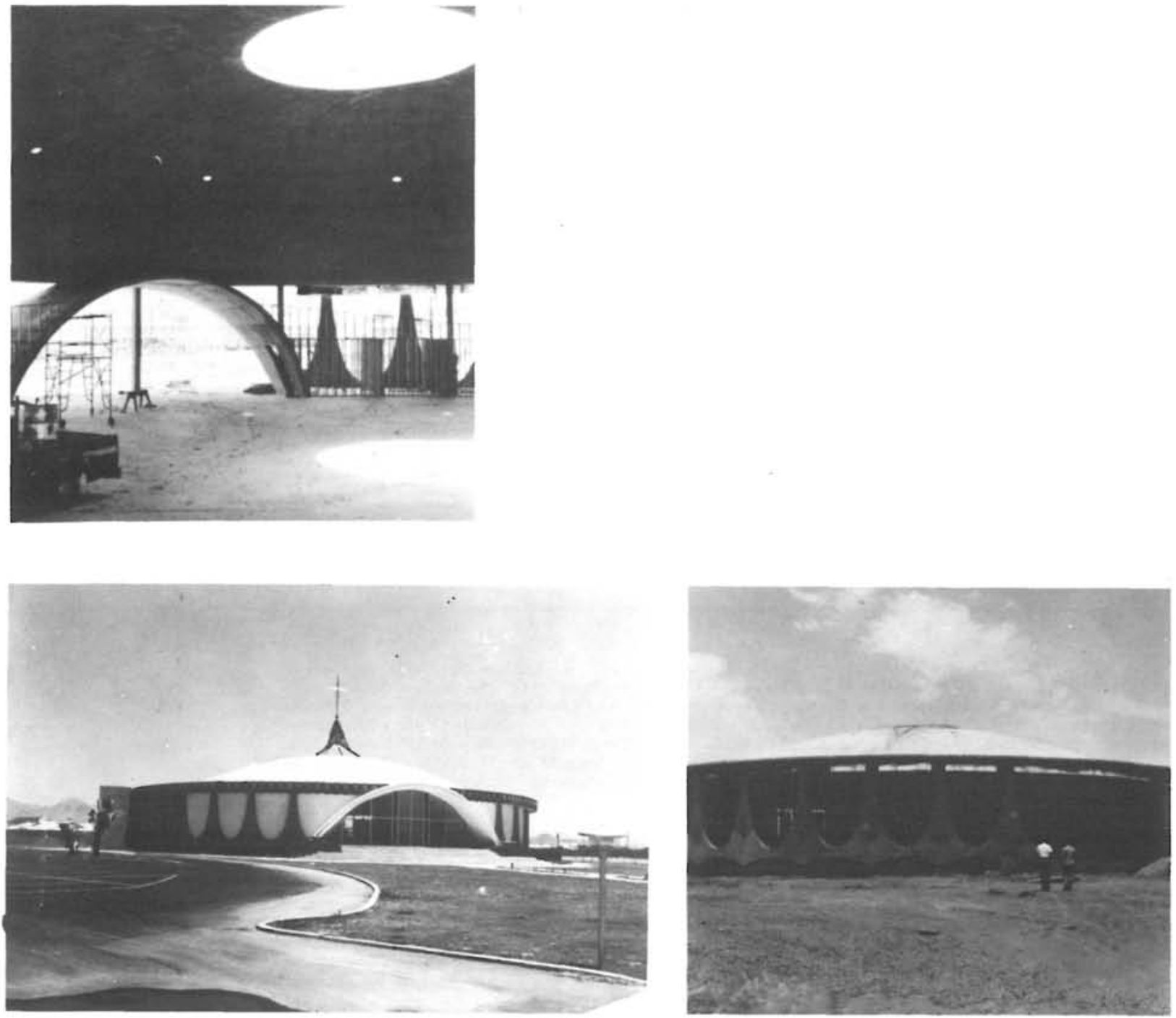


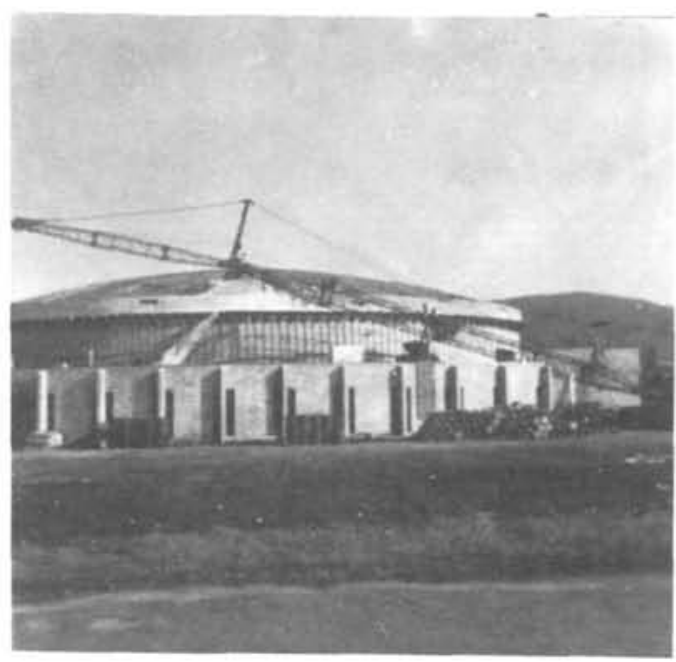

\section{planta, sección y detalles}

Debido a la naturaleza homogénea de la lámina el único revestimiento es una capa de pintura. La chimenea de la residencia forma parte de la estructura laminar; el salón-estar se ha revestido con ladrillo refractario. El aislamiento es una espuma celulosa tratada al fuego. Una característica muy tenida en cuenta en la construcción es que la cantidad de hormigón en toda la bóveda es menor que el volumen de hormigón en la base de la chimenea.
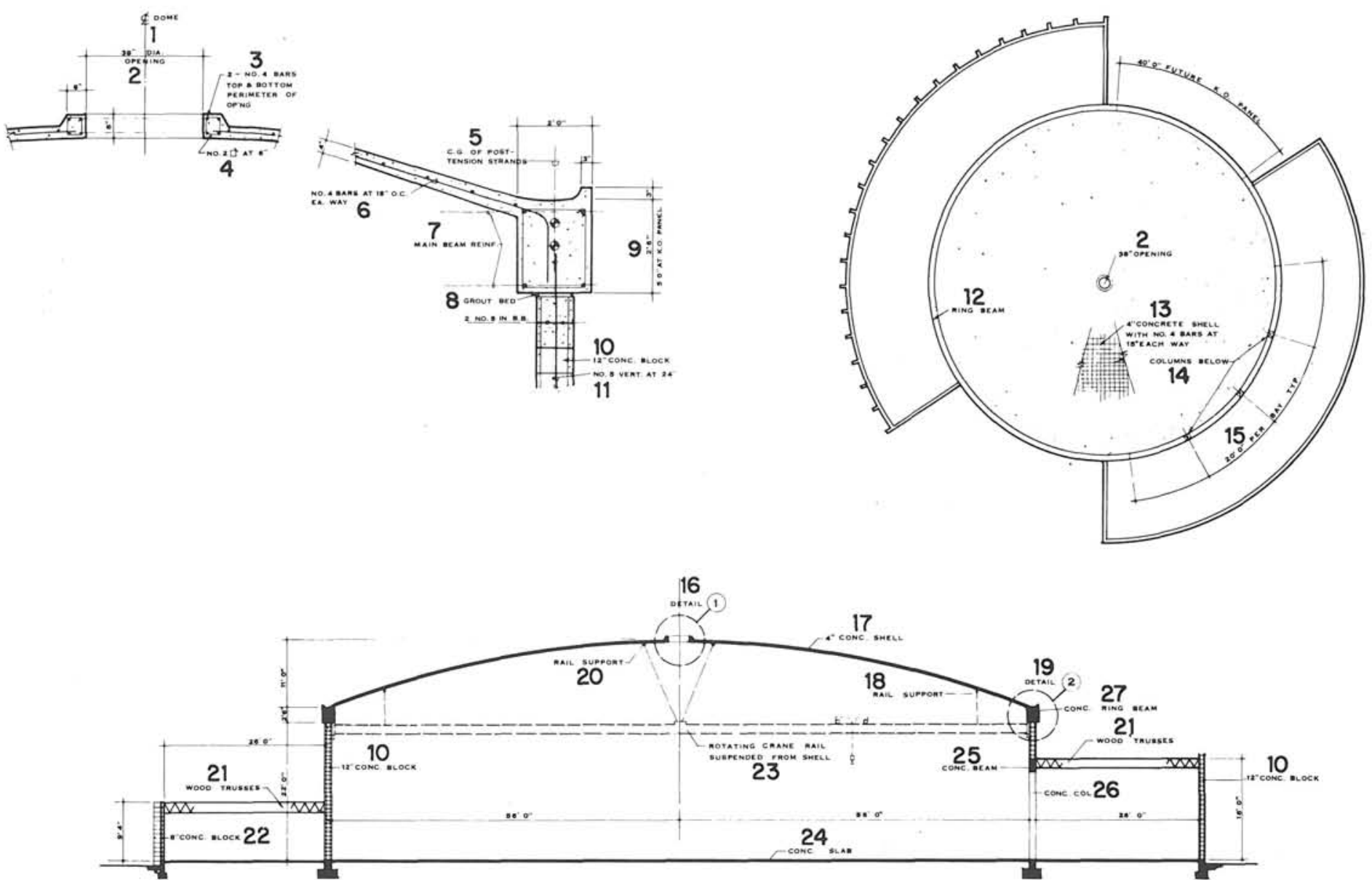

1.-Eje de la cúpula. 2.-Abertura $(965 \mathrm{~mm}$ de Ø). 3.-Anillo armado. 4.-Estribos. 5.-Cable de tensión. 6.-Barras a $381 \mathrm{~mm}$. 7.-Armaduras viga principal. 8.-Junta. 9.-Panel K.O. 10.-Bloque de hormigón de $304 \mathrm{~mm}$. 11.-Armadura vertical a $609 \mathrm{~mm}$. 12.-Viga anular. 13.-Lámina de hormigón con 4 barras a $355 \mathrm{~mm}$ en los dos sentidos. 14.-Pilares. 15.-Vanos de $6.09 \mathrm{~m}$. 16.-Detalle 1. 17.-Lámina de hormigón de $101 \mathrm{~mm}$. 18.-Carril soporte. 19.-Detalle 2. 20.-Carril superior. 21.-Cuchillo de madera. 22.-Bloques de hormigón de $203 \mathrm{~mm}$. 23.-Carril-grúa giratoria colgada de la lámina. 24.-Placa de hormigón. 25.-Viga de hormigón. 26.-Pilares de hormigón. 27.-Viga anular de hormigón.

La mezcla de hormigón, realizada con arena normalizada y hormigón ordinario, se colocó en una tubería de poca presión, justo la necesaria para elevar el hormigón hasta el extremo de la tubería y allí lanzarlo dentro de la superficie. Una vez que el hormigón se «lanzó» dentro de la matriz de acero, hubo de ser forzado por entre el mallado mediante una gran presión aplicada con una llama. Cuando el material comienza a aparecer por la parte inferior, después de haber sido forzado durante todo el camino, se vuelve a trabajar por debajo con una llana. 
El material empleado para el ferrocemento debe ser lo bastante dócil para poder ser forzado entre la malla, pero lo suficiente rígido para permanecer dentro una vez colocado. Se debe usar tan poca agua como sea posible a fin de obtener una mezcla dócil. El mortero se puede aplicar a mano o neumáticamente. El ferrocemento es un material de alta calidad que se puede usar para muchas construcciones. Las capas de malla de alambre y las barras de armadura se encuentran estrechamente adheridas. A veces se usa puzolana, así como cenizas volantes en la relación del 10 por 100 en peso sustituyendo esa misma cantidad de cemento. El material para el ferrocemento es menudo pero, sin embargo, su trabajo es altamente cualificado. Es un material muy homogéneo con muchas pequeñas fisuras, casi invisibles a la vista. El módulo de elasticidad se puede estimar como el de la malla de alambre. El peso de las armaduras será de $480,6 \mathrm{~kg}$ a $640,7 \mathrm{~kg}$ por $\mathrm{m}^{3}$. El ferrocemento tiene un amplio campo de aplicaciones, aunque el volumen mayor se usa en la construcción de barcos.
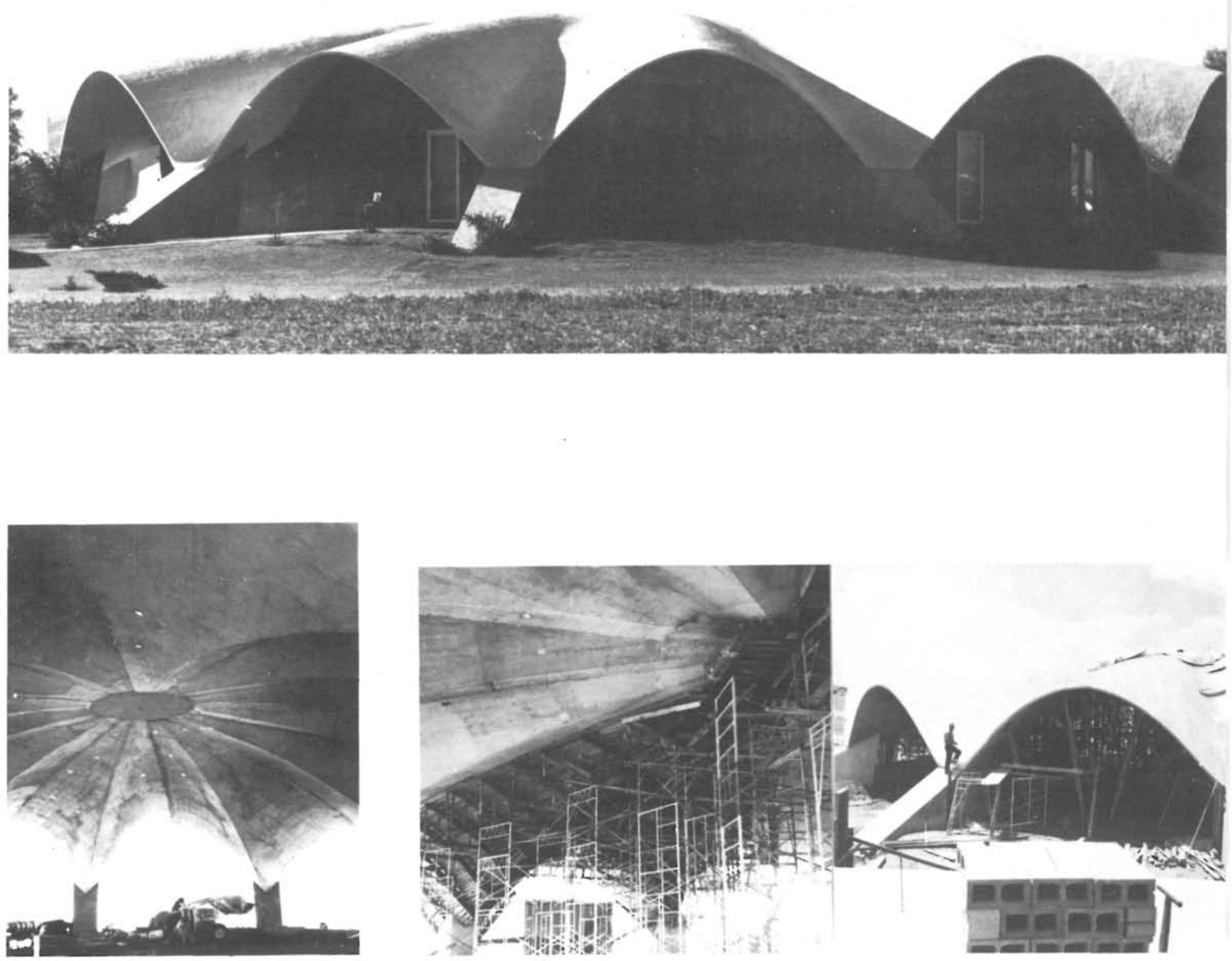


\section{detalles}

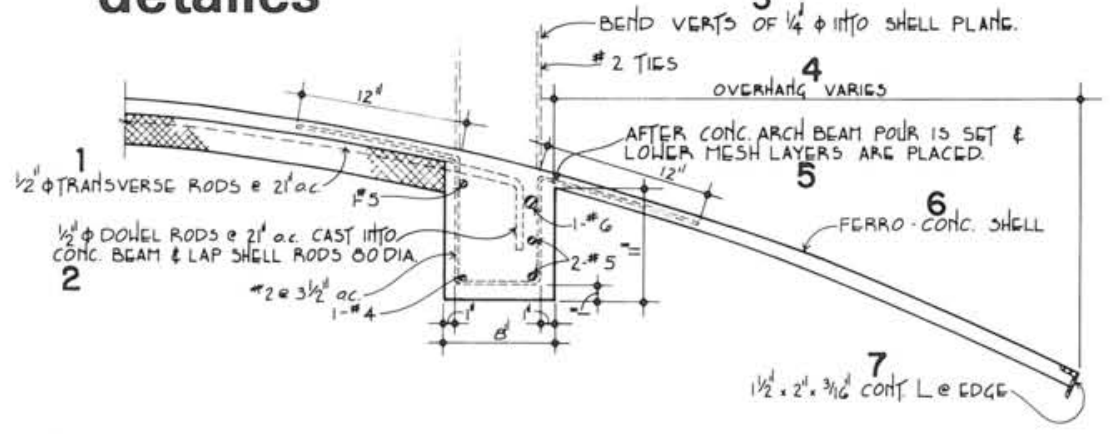

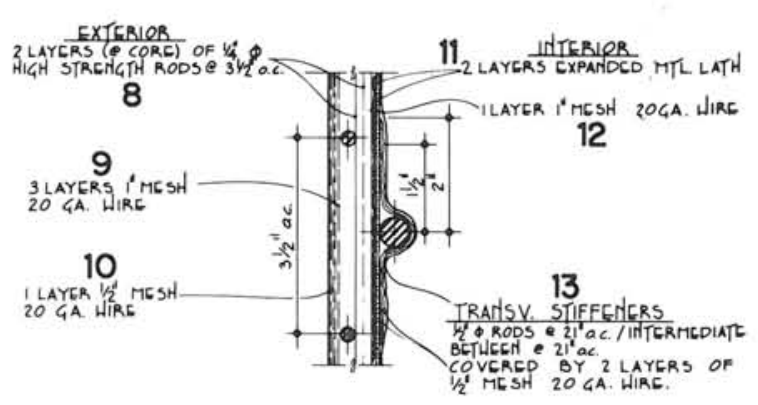

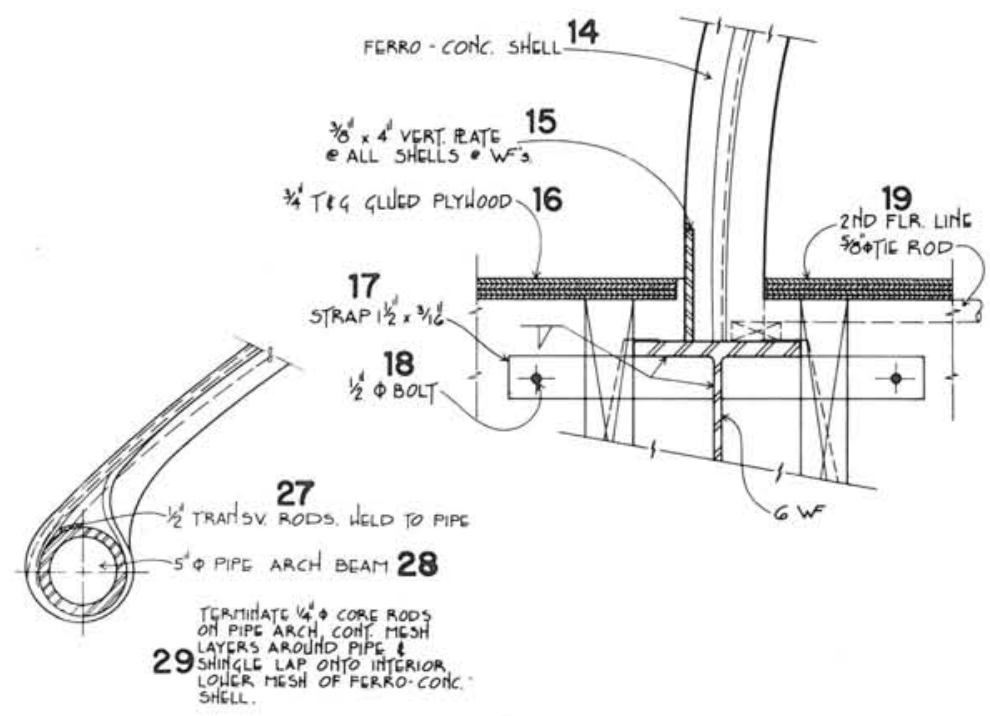

20

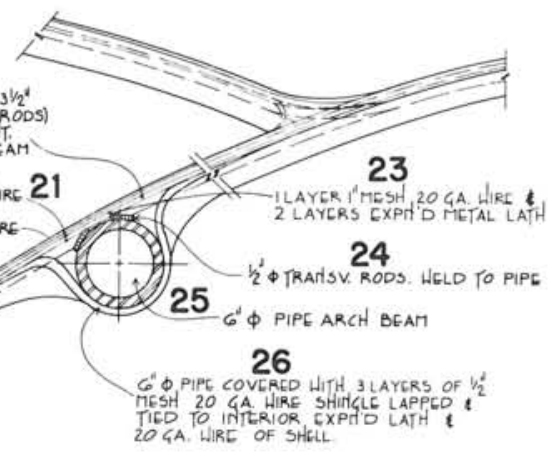

1.-Red transversal ( $\varnothing 12 \mathrm{~mm})$.

2.-Red de la dovela de $12 \mathrm{~mm} \varnothing$ y cada $533 \mathrm{~mm}$ colocada en la viga a $80 \mathrm{~mm} \varnothing$ de la superficie de la lámina.

3.-Bordes cilindricos de $6 \mathrm{~mm} \varnothing$ en la lámina plana.

4.- Pendiente variable.

5.-Después de verter el hormigón de la viga de arco y colocada la capa inferior.

6. - Lámina de hormigón armado.

7.- Angular de $38 \times 50 \times 5 \mathrm{~mm}$.

8.-Dos capas de $6 \mathrm{~mm} \varnothing$ y varillas de $88 \mathrm{~mm}$ de alta tensión.

9.- Tres capas de $25 \mathrm{~mm}$ con malla de alambre.

10.- Una capa de $38 \mathrm{~mm}$ con malla de alambre.

11.-Dos capas metálicas.

12.- Una capa de $25 \mathrm{~mm}$ con nolla de alambre.

13.-Contrafuerte transversal (varillas de $38 \mathrm{~mm} \varnothing$ a $533 \mathrm{~mm}$ cubiertas por dos capas de $38 \mathrm{~mm}$ de malla de alambre).

14.- Lámina armada.

15. - Platabanda vertical de $9 \times 101 \mathrm{~mm}$.

16.-Madera laminada y encolada de $19 \mathrm{~mm}$.

17. - Platabanda de $38 \times 4 \mathrm{~mm}$

18.- Pasador de $12 \mathrm{~mm}$.

19.-Segunda planta (varillas de $15 \mathrm{~mm} \varnothing$ ).

20.-Dos capas de $6 \mathrm{~mm}$ y $88 \mathrm{~mm}$.

21. - Tres capas de $25 \mathrm{~mm}$ y malla con 20 alambres.

22. - Una capa de $12 \mathrm{~mm}$ y malla con 20 alambres.

23. - Una capa de $25 \mathrm{~mm}$ y malla con 20 alambres y dos capas metálicas.

24. Varillas transversales de $12 \mathrm{~mm} \varnothing$ soldadas al tubo

25. - Viga tubular de $152 \mathrm{~mm} \varnothing$.

26. - Tubos de $152 \mathrm{~mm} \varnothing$. Cubiertas con tres capas de $12 \mathrm{~mm}$ y malla de 20 alambres.

27.-Varillas transversales de $12 \mathrm{~mm}$ soldadas al tubo.

28.-Viga tubular de $127 \mathrm{~mm} \varnothing$.

29.-Varillas de $6 \mathrm{~mm}$ sobre el acero tubular cubierta de mallas.

El procedimiento empleado por el constructor fue: realizar primero el encofrado e inyectar después el hormigón. Se fabricaron y colocaron encofrados de vigas trianguladas, con separaciones de 1,22 m. Se usó un entramado de vigas para el encofrado interior, comenzándose primero en las bases de las aristas. El lanzamiento de hormigón duró dos semanas, el tiempo necesario para terminar toda la estructura. Los arcos prefabricados se pusieron con conexiones enclavijadas y se conectaron de manera mecánica en la cúspide. Después de que se retirara el encofrado, el interior recibió un acabado de revoco. El exterior se acabó con un revestimiento de $12,7 \mathrm{~mm}$ espuma de metano. Las zapatas de los cuatro arcos se postesaron juntas. 
Hasta ahora, 7 años más tarde, la estructura ha respondido notablemente bien.

Una iglesia con una estructura laminar de mandera se proyectó y construyó en Tucson, Arizona, USA. Los principales elementos del armazón son tres vigas de madera laminada de $279,4 \mathrm{~mm} \times 1.155,7 \mathrm{~mm}$ que forman tres arcos articulados. La estructura se apoya en contrafuertes de hormigón de 2,13 m de altura.

Un edificio para almacén se construyó en Scottsdale, Arizona, USA, con 48 paraboloides hiperbólicos. Cada lámina tiene unas dimensiones de 15,24 m $\times 15,24 \mathrm{~m}$, con una altura de $2,44 \mathrm{~m}$ y un espesor de $63,5 \mathrm{~mm}$. Las vigas de borde horizontales tienen $190,5 \mathrm{~mm}$ de ancho por $228,6 \mathrm{~mm}$ de canto. Las vigas de borde inclinadas tienen $406 \mathrm{~mm}$ de ancho por $281 \mathrm{~mm}$ de canto y se postensaron con cordones de $\varnothing 12,7 \mathrm{~mm}$ y $1.201 \mathrm{kn}$. Cada paraboloide y su columna correspondiente se proyectaron como una unidad que queda libre, y se unieron mediante pasadores a las láminas adyacentes para formar una alineación vertical.
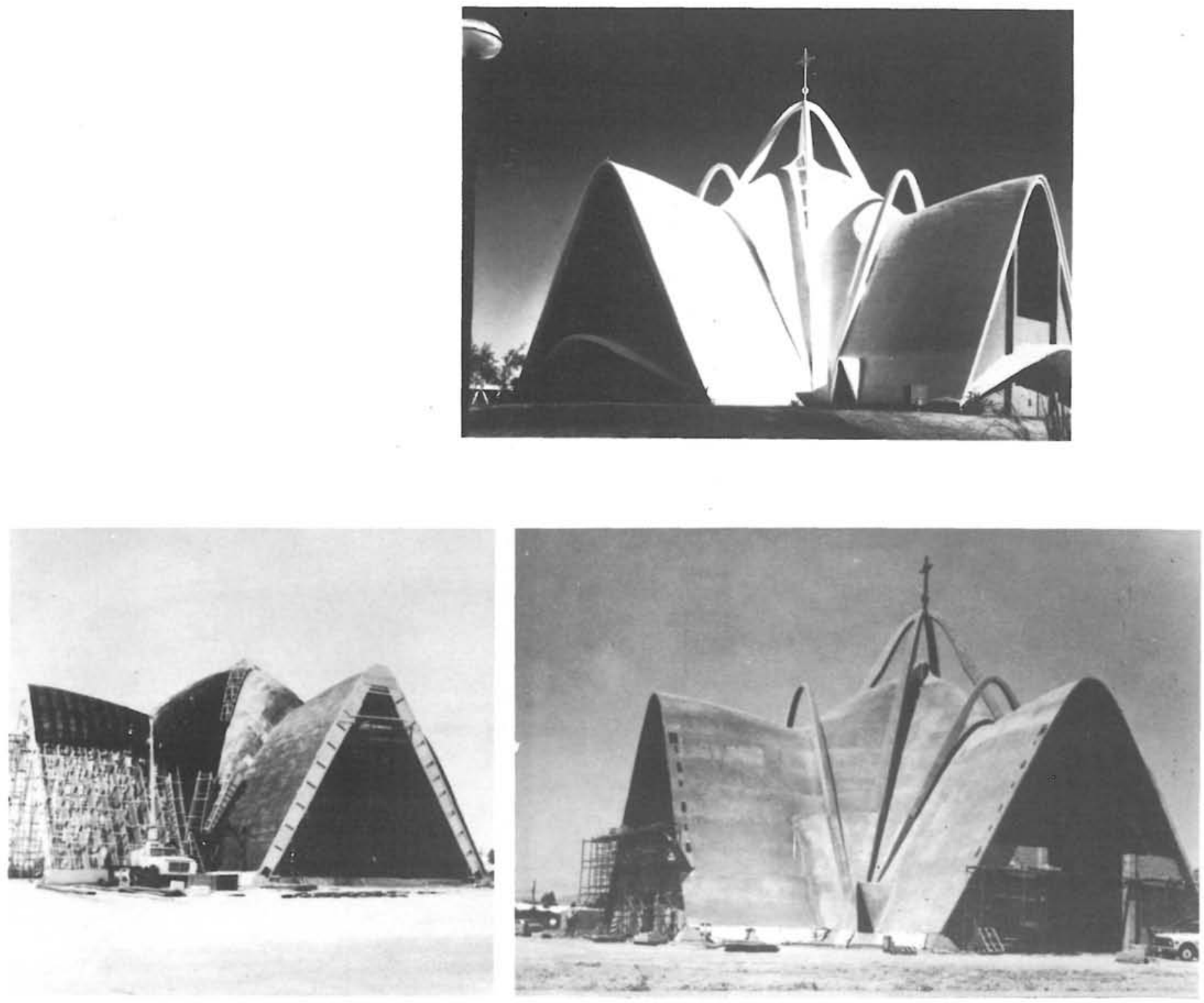

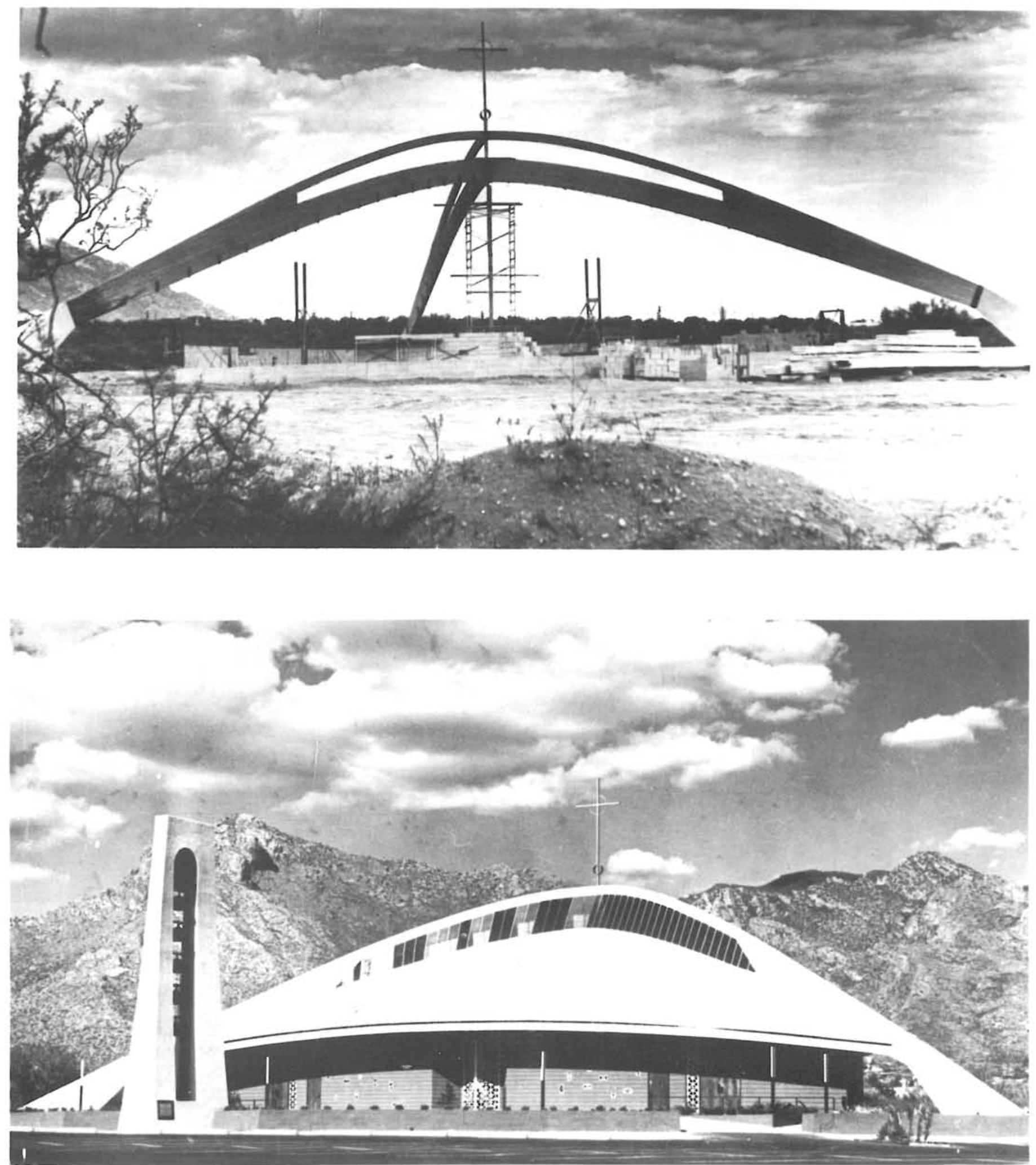

Hay seis láminas en la dirección transversal y ocho alineaciones de arcadas en la dirección longitudinal. El total de los 48 paraboloides hiperbólicos cubre un área de $11.148 \mathrm{~m}^{2}$. El constructor utilizó seis juegos de encofrados, cada uno de ellos de dos secciones y colocados sobre pórticos, con lo que se reducen considerablemente el tiempo y el coste del encofrado. El uso de cada uno de los encofrados ocho veces ayuda asimismo a llevar el coste del encofrado hasta un mínimo. 

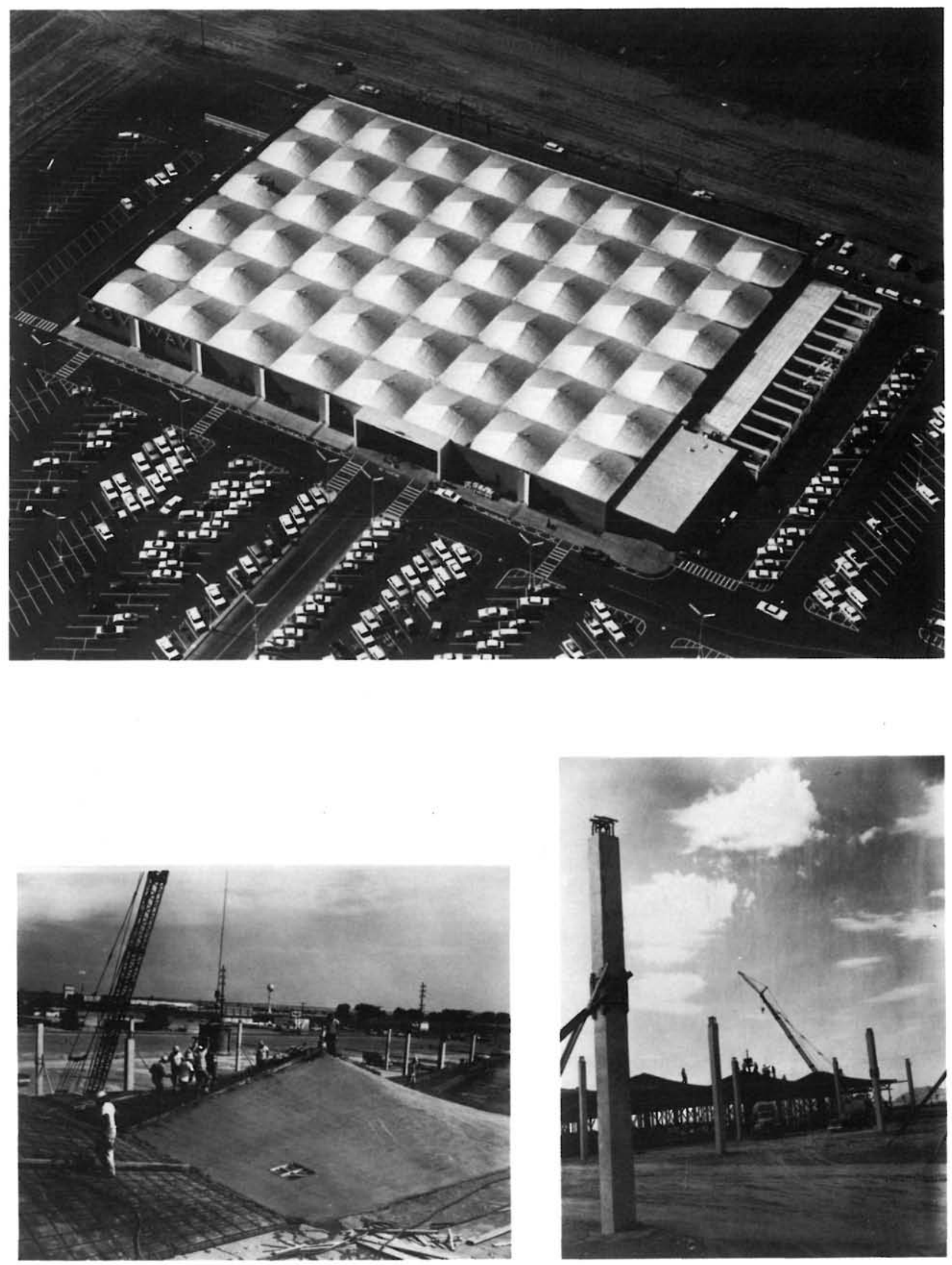

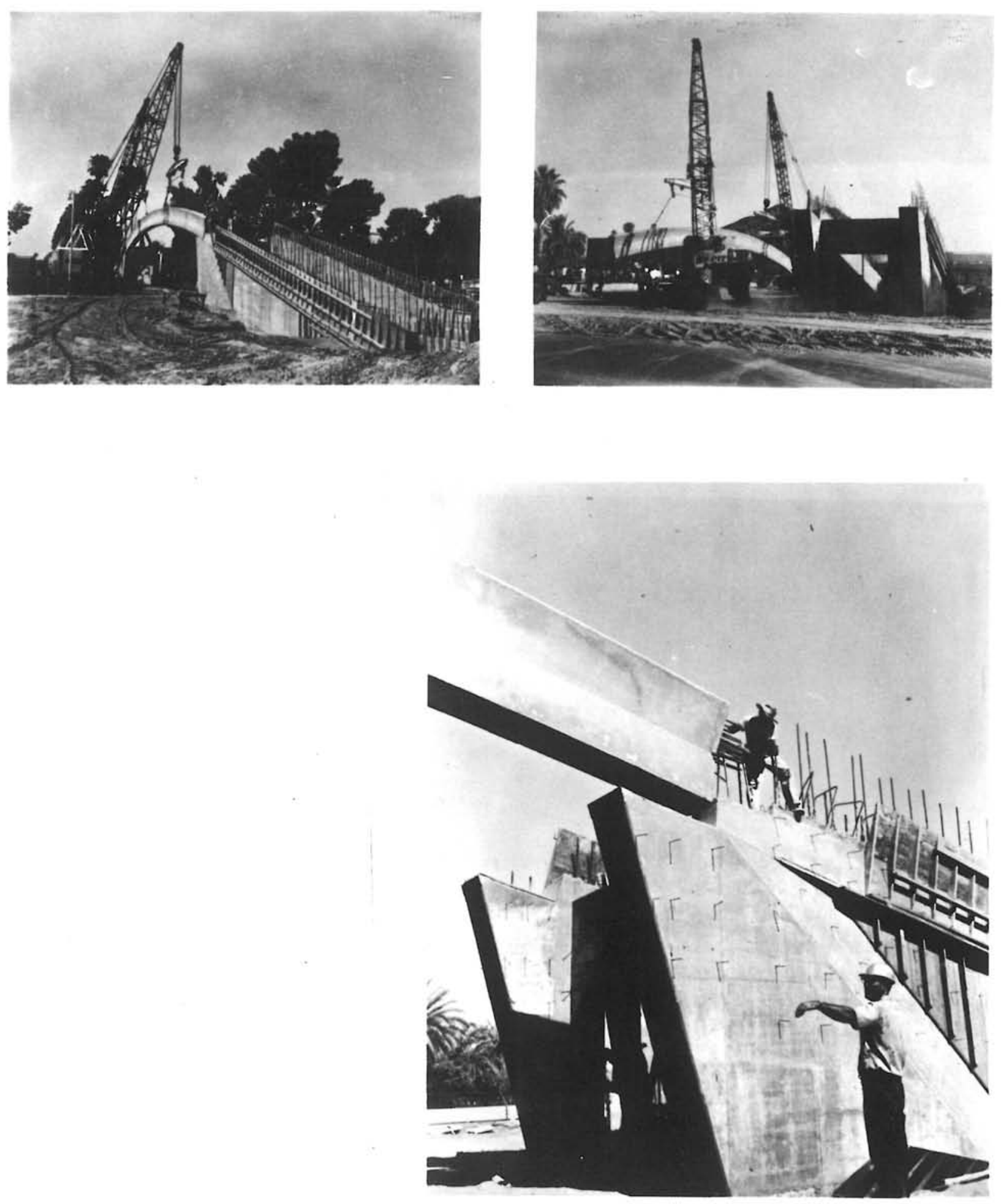

Un puente peatonal se construyó mediante dos vigas-arco, prefabricadas, con una separación de $30,7 \mathrm{~m}$. Las vigas tienen $1,37 \mathrm{~m}$ de canto y un promedio de $0,44 \mathrm{~m}$ de ancho. Se prefabricaron y se postensaron con un esfuerzo de postensado de $224 \mathrm{kn}$ antes de la erección. Después se colocaron las vigas in situ y se volvió a aplicar un postensado de 224 kn.

Dos paraboloides hiperbólicos de $76,2 \mathrm{~mm}$ de espesor, con una distancia de $30,48 \mathrm{~m}$ entre apoyos, se han usado para edificios bancarios. La viga de borde es gradualmente delgada, desde $812,8 \mathrm{~mm}$ en el extremo, hasta $177,80 \mathrm{~mm}$ en el borde exterior. Los apoyos se postensaron juntos en las bases correspondientes. 
